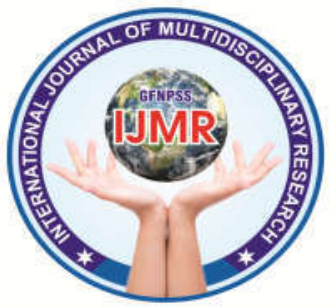

ISSN (0): 2582-693X

Original Article

\title{
EFFECT OF PERIODONTAL HEALTH STATUS IN IMPROVED TYPE-2 DIABETES MELLITUS
}

\section{DR. GULJOT SINGH ${ }^{1}$ DR. ROHAN VASANTH RAJ ${ }^{2}$ DR.GARGI SHARMA ${ }^{3}$}

${ }^{1}$ Principal \& Head, Department of Periodontology, Daswani Dental College and Research Centre, Kota, Rajasthan

${ }^{2,3}$ Post Graduate Student, Department of Periodontology, Daswani Dental College and Research Centre, Kota, Rajasthan

Corresponding Email: docguljot@gmail.com,drrohanvasanthraj@gmail.com nikhilpholey@gmail.com

\begin{abstract}
Aim: To compare the clinical and metabolic changes following non-surgical periodontal treatment (pre and post), in diabetic (Type 2) patients

Materials and Method: A prospective, interventional, comparative, clinical study was carried out on 40 type 2 diabetic patients with generalized chronic periodontitis. Group I (Control group) - consisted of 20 patients with type II Diabetes Mellitus who were not be subjected for scaling and root planning. Group II (Study group) consisted of 20 patients with type II Diabetes Mellitus who were subjected for scaling and root planning. Plaque index (Sillness and Loe) Gingival bleeding index (Loe and Sillness) Probing pocket depth Clinical attachment level and gingival recession was calculated.
\end{abstract}

Result: No statistical differences on clinical parameters (PI, HBA1C and RBS) and statistically significant differences for clinical parameters (GI, PPD reduction) were seen between test and control sites.

Conclusion: Subjects with type-2 diabetes have an increased risk of destructive periodontitis with an odds ratio of 2.81 when attachment loss is used to measure the disease. These findings demonstrate That periodontitis should be considered a potential complication of diabetes in evaluation of patients.

Keyword:Effect,Periodontal Health Status, Type-2 Diabetes Mellitus

INTRODUCTION:

Diabetes Mellitus, the most widespread infection of mankind, is a syndrome characterized by chronic hyperglycaemia and disturbance of carbohydrate, fat and protein metabolism associated with absolute or relative 


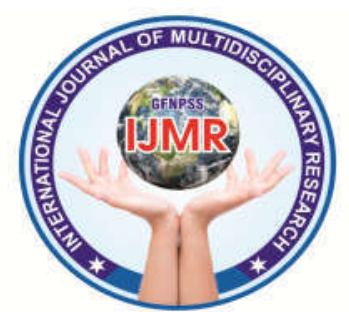

deficiencies in insulin secretion and/or insulin action. Prevalence of diabetes in adults worldwide was estimated to be $4.0 \%$ in 1995 and predicted to rise to $5.4 \%$ in the year $2025^{[2]}$. It is higher in developed than in developing countries. The number of adults with diabetes in the world will rise from 135 million in 1995 to 300 million in the year $2025^{[2]}$. There will be $42 \%$ increase, from 51 to 72 million, in the developed countries and a $170 \%$ increase from 84 to 228 million, in the developing countries ${ }^{[3]}$. Recent WHO reports show that India already has the largest number of diabetic patients in the world $^{[3]}$, making it the "Diabetes Capital of the World". Prevalence of periodontal disease among individuals with inadequately controlled type-2 diabetes mellitus is generally higher than that of people free of systemic disorder ${ }^{[1] . S c i e n t i f i c ~ e v i d e n c e ~ o n ~ t h e ~ e f f e c t s ~ o f ~}$ periodontal disease and diabetes has emerged lately. Various studies have correlated response to periodontal treatment in diabetic patients and its influence on their metabolic control ${ }^{6}$.The treatment of periodontitis or other infections of the oral cavity can improve glycaemic control in diabetic patients. Thereappears to be clear clinical and epidemiologic evidence in the literature that periodontal disease worsens glycaemic control in diabetes. The aim was to test the hypothesis that diabetic patients have more severe periodontal disease experience, ascertain whether there is any influence of non-surgical periodontal therapy in periodontal health status.

\section{MATERIALS AND METHODS:}

40 subjects with type 2 diabetes mellitus with generalized chronic periodontitis were taken for the study from the outpatient Department of Periodontics, Daswani Dental College \& Research Centre, Kota, Rajasthan. The aims and objectives of the study along with the duration and method was elaborated and explained to the subjects. Subjects included were 18 men and 22 women. As per exclusion criteria, patients with smoking habits, with systemic complications other than diabetes mellitus, women with pregnancy, patients on anticoagulation therapy, patients with a history of antibiotic therapy, and periodontal treatment for the past 6 months were not included in the study. 


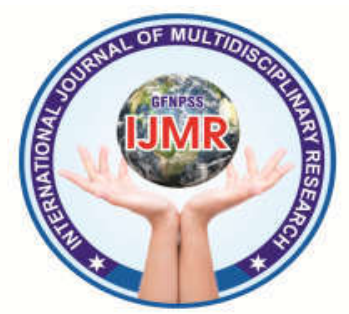

\section{PATIENT SELECTION:}

Study consisted of 2 groups: After randomization by computer software.

Group I - (Control group) - consisted of 20 patients with type II Diabetes Mellitus who were not be subjected for scaling and root planning.

Group II (Study group) consisted of 20 patients with type II Diabetes Mellitus who were subjected for scaling and root planning.

Procedure:

All subjects were asked to report to the clinic after fasting overnight (8-12 hours) and the recordings of the dental status were made. The following dental variables were measured;Plaque index (Sillness and Loe)Gingival bleeding index (Loe and Sillness) Probing pocket depth, Clinical attachment level and gingival recession.

1. Group I (test group)

2. Group II (controlgroup).

Treatment Regimen

Conventional periodontal treatment ,scaling and root planning under local anaesthesia (if necessary) was carried out After scaling and root planning, following periodontal parameters were recorded at baseline:

Plaque Index (PI), Silness P and

Loe H., (1964)

Gingival Index (GI), Loe $\mathrm{H}$ and Silness P, (1963)

Probing pocket depth (PPD)
Glycated Haemoglobin (HbAlc test), NycoCard READER II (For assessing Glycated Haemoglobin),

Random blood sugar test, Glucometer (For assessing Random blood sugar)

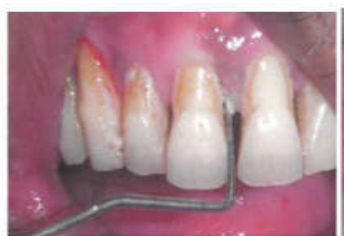

Probing pocket depth (PPD) at base line

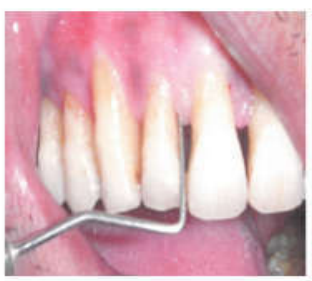

Probing depth (1month)

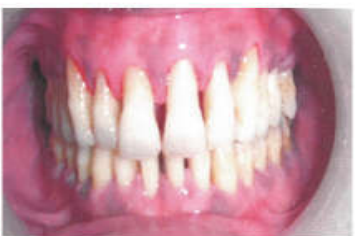

After scaling and root planning

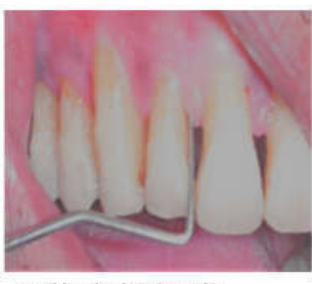

Probing depth ( $3^{\text {rd }}$ month)

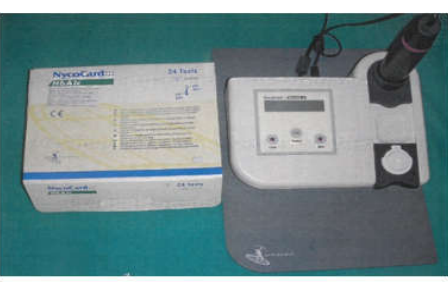

NycoCard READER II (For assessing Glycated Hemoglobin)

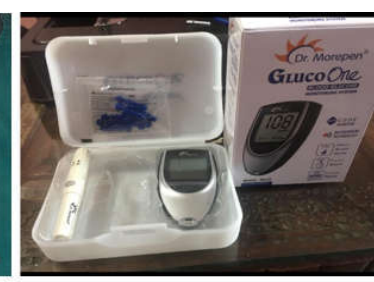

Glucometer

\section{RESULTS:}

It was observed that intergroup (Test and Control groups) comparisons of plaque index, 


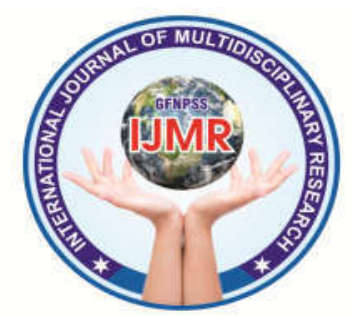

gingival index and periodontal $\mathrm{p}>0.05$ is statistically not significant and pocket depth showed statistically significant difference and intra group comparison of Plaque index is not statistically significant and Gingival index is statistically significant at baseline and $3^{\text {rd }}$ month.

The study group showed a reduction in HbA1c from $6.9450 \pm .96599$ to 6.6944 \pm .84260 and was not considered to be statistically significant. The control group showed an increase from $6.7750 \pm$ .75803 to $7.5500 \pm .58264$ at the end of the $3^{\text {rd }}$ month, these changes was found to be very highly statistically significant. There was no statistically significant difference between the study group and the control group for the $\mathrm{HbAlc}$ value at the end of the $3^{\text {rd }}$ month.

In the test group there was a reduction in the mean random blood sugar levels from $118.0500 \pm 20.18461$ to 113.7778 \pm 12.32193 and in the control group from $117.7500 \pm 20.38543$ to $114.6000 \pm$ 11.27363 at the end of the $3^{\text {rd }}$ month. The changes were not statistically significant, At the end of the $3^{\text {rd }}$ month the random blood sugar level was not statistically significant when compared between the $\mathrm{P}<0.05$ is statistically significant

\section{STATISTICAL ANALYSIS:}

The results are given as mean and standard deviation values. To compare the two groups, $t$ paired and $t$ unpaired test was used.

\section{CLINICAL PARAMETERS: \\ Random Blood Sugar:}

Table I- Comparison of RBS study and control group at baseline and $3^{\text {rd }}$ month

\begin{tabular}{|l|c|c|c|c|}
\hline Groups & N & Mean & Std.Deviation & P value \\
\hline Base & 20 & 118.0500 & 20.18461 & $0.989 \mathrm{~ns}$ \\
Study \\
Control & 20 & 117.7500 & 20.38543 & \\
\hline 3 Months & 20 & 113.7778 & 12.32193 & $0.965 \mathrm{~ns}$ \\
Study & & & \\
Control & 20 & 114.6000 & 11.27363 & \\
\hline
\end{tabular}

Graph I-Comparison of Random blood sugar levels within the study and control groupat baseline and $3^{\text {rd }}$ month

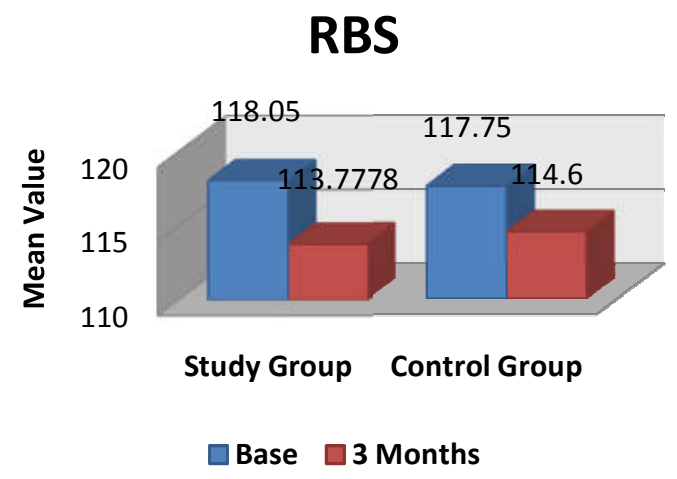
test and the control group. 


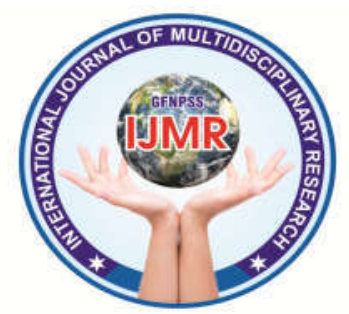

HbA1C:

Table II- Comparison of Hba1c between study and control group at baseline and $3^{\text {rd }}$ month

\begin{tabular}{|l|c|c|c|cc|}
\hline Group & N & Mean & $\begin{array}{c}\text { Std. } \\
\text { Deviation }\end{array}$ & P value \\
\hline Base & 20 & 6.9450 & 0.96599 & 0.575 & ns \\
$\begin{array}{l}\text { Study } \\
\text { Control }\end{array}$ & 20 & 6.7750 & 0.75803 & & \\
\hline $\begin{array}{l}\text { M Months } \\
\text { Study } \\
\text { Control }\end{array}$ & 20 & 6.6944 & 0.84260 & 0.002 & vhs \\
\hline
\end{tabular}

\section{GraphII-Comparison of Hba1c values} in the study and control group at baseline and $3^{\text {rd }}$ month

\section{HbA1c}

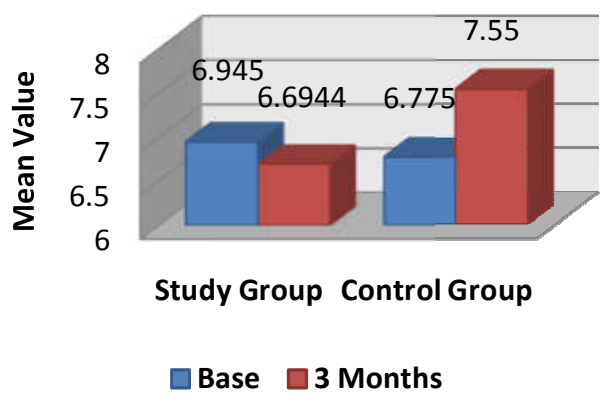

\section{DISCUSSION:}

The term "Diabetes Mellitus" refers to a chronic disease of the pancreas that causes the body to produce insufficient amount of insulin or is caused by the inability of the body to utilize the insulin produced in the correct manner ${ }^{[2] .}$

Periodontal disease is often referred to as the sixth long-term complication of diabetes, but it often goes unrecognized by physicians who treat diabetic patients $^{[3]}$. People with diabetes are much more susceptible to periodontal disease and once periodontal disease is established in a diabetic patient, metabolic control (glycaemic control or blood sugar levels) of diabetes is complicated from the constant reservoir of gram-negative anaerobic bacteria that are present in the pocket initiating infection and mediating low-grade inflammation throughout the body ${ }^{[4]}$ Thus, the relationship between diabetes and periodontal disease is sometimes referred to as a two-way, and the reason why diagnosis and treatment of periodontal disease, just like optimal glycaemic control, are essential in the medical management of diabetes ${ }^{[5]}$.

A number of possible mechanisms have been proposed by which diabetes may affect the periodontium. These are primarily related to changes in the subgingival microbiota, GCF glucose levels, periodontal vasculature, host 


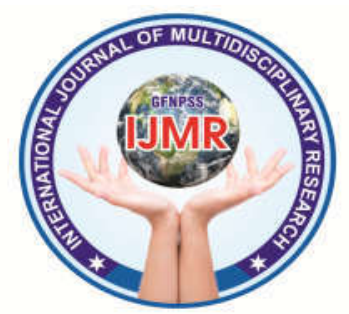

response and collagen metabolism.

Difference between diabetic and non diabetic individuals in the primary bacterial etiologic agents of periodontal disease suggests that increased prevalence and severity of periodontitis in diabetes may be due to difference in host response factors ${ }^{[6,7]}$

Hyperglycaemia adversely affects the synthetic maturation and maintenance of collagen and extracellular matrix. In hyperglycaemic state, numerous proteins and matrix molecules undergo a nonenzymatic glycosylation, resulting in advanced glycation end products ${ }^{[9]}$.

AGE formation cross-links collagen, making it less soluble and less likely to be normally repaired or replaced, resulting into increased breakdown of collagen. AGE play a central role in the classic complication of diabetes [10]. In a study by Almas et al. in 2001 at the King Saud University, College of Dentistry, 40 subjects were examined, 20 in each group of healthy and diabetic subjects, with ages ranging from 20 to 70 years.It was observed that the severity of periodontal disease increased with the increase in the blood glucose level. There was a steady increase in blood glucose level with increase in CPITN scores ${ }^{[11]}$.

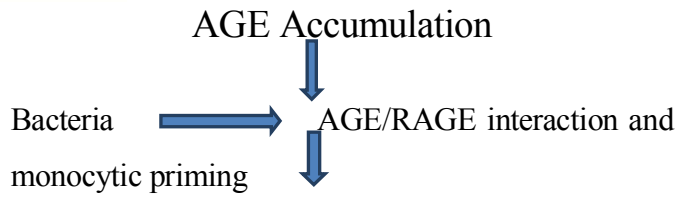

Hyper-inflammatory response<smiles>C=CC</smiles>

Increased cytokine expression Severe TNF $\alpha$, IL-1 $\beta$, IL-6, PGE $_{2}$

Tissue and Bone Destruction

Fig: Possible linkage between diabetes and periodontal disease severity.

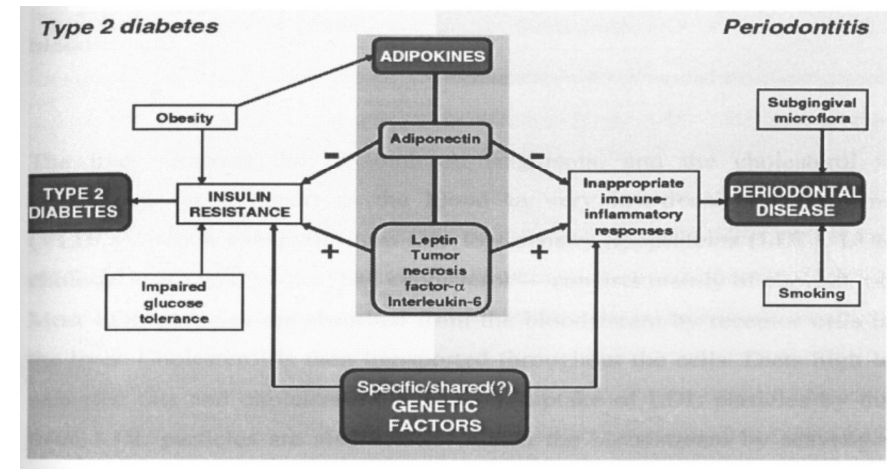

Proposed model to demonstrate central role of adipokines in crosssusceptibility between type 2 diabetes mellitus and periodontal disease CONCLUSION:

Diabetic status was significantly and strongly related to both the prevalence and severity of disease after adjusting for effects of demographic variables and several indices of oral health including plaque index. Subjects with type- 2 diabetes have an increased risk of destructive periodontitis with an 


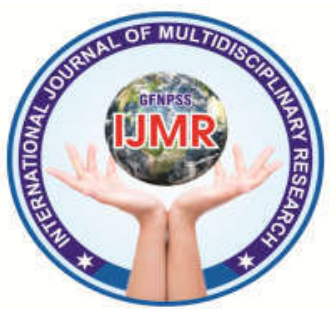

odds ratio of 2.81 when attachment loss is

06. Ricardo Faria, Navarro Ana. Clinical used to measure the disease. These and metabolic changes after findings demonstrate that periodontitis should be considered a potential complication of diabetes in evaluation of patients.

\section{REFERENCES:}

01. Kahr CR, Weire GC, Lea \& Febiger. Joslin's diabetes mellitus, $13^{\text {th }}$ ed. Philadelphia 1994; 193-194.

02. WHO Diabetes Mellitus. Report of a WHO study group. Technical report series No. 727, WHO Geneva 1985.

03. King H, Aubert RE, Herman WH. Global burden of diabetes. Prevalence numerical estimates and projections.

Diabetes care 1998; 21(9): 1414-31.

04. Davidson's. Principles and practice of medicine $19^{\text {th }}$ ed: $644-655$.

05. Stewart JE, Wager KA. The effect of periodontal treatment on glycemic control in patients with type 2 diabetes mellitus. JClin Periodontol 2001; 28(4): 306-310.

Conventional treatment of type 2 diabetes patients with chronic periodontitis. JPeriodontol 2006; 77(4):591-598.

07. Brain L. Mealey \& Gloria L. Ocampo. Diabetes mellitus and periodontal disease. Perio 2000, 2007; 44:127253.

08. George W Taylor: bidirectional interrelationships between diabetes and periodontal diseases. An epidemiolog ical perspective: Ann Periodontol 2001;6(1):99 - 110.

09. Burket's-Oral Medicine diagnosis and treatment: $10^{\text {th }}$ ed: $563-577$.

10. Textbook of Nutrition and oral medicine: Riva Touger-Decker, David A, Sirois, Connie C. Mobley: 185-204. 11. Preshaw PM, Alba AL, Herrera D, Jepsen S, Konstantinidis A, Makrilakis $\mathrm{K}$, et al. Periodontitis and diabetes: A two-way relationship. Diabetologia 2012;55(1):21-31 